This is a repository copy of Fuzzy based state observer of a solar trough field in the Depósito de Investigación de la Universidad de Sevilla

Version: Author Accepted Version

Citation: Fuzzy based state observer of a solar trough field. Adolfo J. Sanchez, Juan Manuel Escano, Carlos Bordons, Eduardo F. Camacho. 2019 30th Irish Signals and Systems Conference (ISSC). 10.1109/issc.2019.8904927

To cite this publication, please use the final published version (if applicable). Please check the document version above.

Copyright: Other than for strictly personal use, it is not permitted to download, forward or distribute the text or part of it, without the consent of the author(s) and/or copyright holder(s), unless the work is under an open content license such as Creative Commons.

Takedown policy: Please contact us (idus@us.es) and provide details if you believe this document breaches copyrights. We will remove access to the work immediately and investigate your claim 


\title{
Fuzzy based state observer of a solar trough field
}

\author{
Adolfo J. Sánchez*, Juan Manuel Escaño ${ }^{\dagger}$, Carlos Bordons ${ }^{\ddagger}$ and Eduardo F. Camacho ${ }^{\S}$ \\ Dept. of System Engineering and Automatic Control. Universidad de Sevilla. \\ Camino de los Descubrimientos $s / n$. 41092. Sevilla. Spain \\ Email:*asanchezdelpozo@us.es, ${ }^{\dagger}$ jescano@us.es, ${ }^{\ddagger}$ bordons@us.es, §efcamacho@us.es
}

\begin{abstract}
The estimation of unobservable states of a process is important when using control techniques that assume, said a priori, known values. The controllers based on the state space present good behavior and efficiency, even when the dynamics of the process are non-linear. One of the processes with non-linear dynamics and in which not all the states are observable is the case of parabolic trough solar plants. In this work an observer is presented, based on a fuzzy inference system, for the estimation of the temperature profiles of the loops that make up the solar field. This is a English translation of an earlier work presented in the XXXIX Spanish workshop in Automatic Control [15].
\end{abstract}

Index Terms-Fuzzy estimator, parabolic trough solar plants, Model Predictive Control.

\section{INTRODUCTION}

In the automatic control of industrial processes, the more information about the process is sent to the controller, the better the control will be.

The information that can be provided to the controller, will depend in all cases on the type of controller that has been designed. In the case of classic controllers such as a Proportional Integral Derivative (PID) control, the only information that will be received is the error between the reference and the output of the system to be controlled. The knowledge of the status of the plant in the controller is limited to an error signal. In other more complex controllers, the information that can be provided is greater. Complex controllers are, generally, used to control systems with high non-linear dynamics. Model Predictive Control (MPC) techniques have become popular. The state space MPCs controllers need to know the value of the different states of the system. These states may or may not be observable. If they can not be measured by physical or even economic impossibility, they can be estimated and the controller can use the estimates as if they were measures. A particular case where not all states can be measured, mainly due to economic reasons, is a parabolic trough solar plant. These plants are formed by numerous loops of solar collectors of hundreds of meters [9], [13], [16], [17]. Given the nonlinear nature of the solar field process, multiple MPC control techniques have been designed in the state space, obtaining good results. In [6], the authors propose an adaptive model MPC in the space of states for the control of the solar field with an estimation by Unscented Kalman Filter (UKF). A more advanced MPC in the state space is presented in [7] where a Luenberguer observer is proposed for the estimation of the states. An Extended Kalman Filter (EKF) is proposed in [12] for the estimation of the temperatures of internal loop and input assuming that there is no sensor to the input and its application in a PID. In [14], the authors presented a nonlinear optimization to control the input valves. The optimzation problem is solved using a reduced non-linear model in which the states are estimated by means of a Classification and Regression Trees (CARTs) observer. The linear estimators, like Luenberguer observer, are based on the linear model of the plant that is nothing more than an approximation of the nonlinear model. Therefore, prediction errors are expected in the estimation of the states. On the other hand, estimators based on data, as in the case of CARTs, can provide small error values if they are well designed, although at a higher computational cost due to the size that the estimator will occupy in memory. Although, generally, a small error is not a concern for control, the aim is to keep it as low as possible with the lowest computational cost.

This work deals with the estimation of the states of the solar field based on Fuzzy Logic.

Fuzzy Inference Systems (FIS) systems are generic functional approximations, that is, given a certain level of error, it is possible to find a FIS that approximates any function with an error lower than the fixed one. This makes the FIS suitable to be used as estimators and they do not even have to be based on the state space necessarily. Many methods can be found in the literature for the identification of a FIS. One of the most popular methods is the formulation of a Takagi-Sugeno fuzzy system (TS) [18] as a Neural Network (NN) [11], also called Adaptive Neuro-fuzzy Inference System (ANFIS). One of the classic ways to, experimentally, model complex systems is through the use of artificial NN. A FIS, used for estimation, can handle non-linear systems and provide system knowledge. In this work we propose a fuzzy TS-type system with Gaussian membership functions, of the type:

$$
m(x ; c, \sigma)=e^{-\frac{1}{2}\left(\frac{x-c}{\sigma}\right)^{2}}
$$

with a set of rules $R_{j}$ :

IF $x_{1}(k)$ is $F_{1 j}$ and $x_{2}(k)$ is $F_{2 j}$, THEN:

$y_{j}(k)=a_{1 j} x_{1}(k)+a_{2 j} x_{2}(k)+a_{3 j}$, where $a_{i j} \in \mathbb{R}$

There are many learning algorithms applicable to ANFIS to update the parameters of the layers. Notably, for example, Backpropagation (BP) [19], has been used a lot in NN design. There are other methods combined with BP, such as the hybrid 
combination of least squares and backpropagation, [11], [8]. One of the advantages of fuzzy systems versus NNs is the possibility to add "expert" rules. These rules are given by the engineer's expert knowledge and observation of the system. As discussed above, one of the most important properties of the FIS is its ability to approximate nonlinear functions with bounded approximation error. Improving accuracy may cause an increase in the number of rules. It should be considered that a system based on too many rules may not be practical and causing a loss of understanding of the system. The use of a grouping method can avoid the explosion of rules and obtain the natural clusters between the input and output variables. In this paper, some popular and widely used techniques are presented to obtain the structure and train the FIS to adjust to the real data.

The paper is organized as follows: Section II presents the Acurex solar field model and the mathematical models used in this work. In Section 3 we present the design of the fuzzy estimator for the loop states of the Acurex field. Section 4 shows the results obtained with the fuzzy estimation in two different simulated scenarios. Finally, Section 5 draws to an end with some conclusions.

\section{ACUREX SOLAR FIELD}

The ACUREX field, located in the Plataforma Solar de Almería, is a solar field with 480 parabolic trough collectors. The collectors are arranged in 10 loops. The total length of each loop is $172 \mathrm{~m}$, which includes active parts $(142 \mathrm{~m})$ and passive parts, that is, junctions and other parts that do not reach the concentrated solar radiation $(30 \mathrm{~m})$.

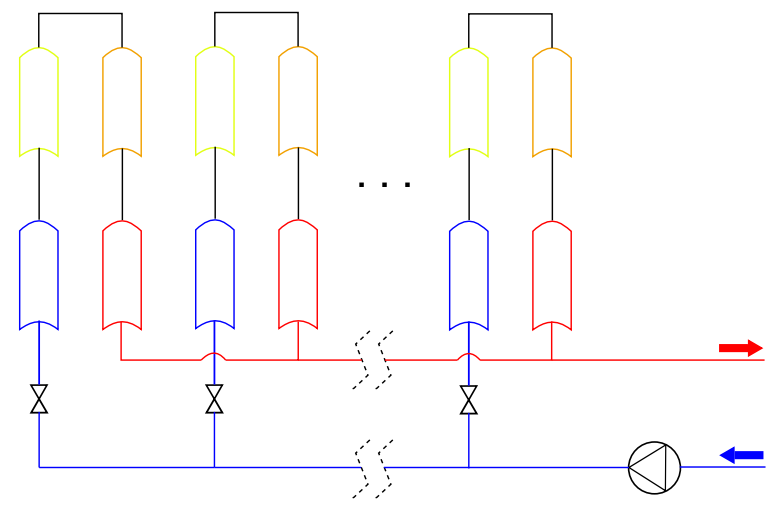

Fig. 1: Acurex Solar Field schematic.

In this paper, two types of mathematical models are used for the plant: a distributed parameter model and a concentrated parameter model. Both models have been obtained through tests and validations carried out at the plant and have been used by many authors. A schematic of the plant is shown in Fig. 1. For a full description of the plant modeling procedure, see [2], [3].

\section{A. Distributed parameters model}

The dynamics of the distributed solar collector field is described by the following system of partial differential equa- tions (PDE) that describe the energy balance that occurs in the loop [2], [3]:

$$
\begin{aligned}
& \rho_{m} C_{m} A_{m} \frac{\partial T_{m}}{\partial t}=I K_{o p t} n_{o} G-H_{l} G\left(T_{m}-T_{a}\right) \\
&-L H_{t}\left(T_{m}-T_{f}\right) \\
& \rho_{f} C_{f} A_{f} \frac{\partial T_{f}}{\partial t}+\rho_{f} C_{f} \dot{q} \frac{\partial T_{f}}{\partial x}=L H_{t}\left(T_{m}-T_{f}\right)
\end{aligned}
$$

where the subscript $m$ refers to the metal and $f$ refers to the fluid. The parameters and units of the model are shown in Table I.

TABLE I: Parameters description.

\begin{tabular}{lll}
\hline Symbol & Description & Unit \\
\hline$t$ & Time & $\mathrm{s}$ \\
$x$ & Space & $\mathrm{m}$ \\
$\rho$ & Density & $\mathrm{kg} / \mathrm{m}^{3}$ \\
$C$ & Specific heat capacity & $\mathrm{J} /\left(\mathrm{kg}^{\circ} \mathrm{C}\right)$ \\
$A$ & Cross-sectional area of the pipe & $\mathrm{m}^{2}$ \\
$T$ & Temperature & ${ }^{\circ} \mathrm{C}$ \\
$T_{a}$ & Ambient temperature & ${ }^{\circ} \mathrm{C}$ \\
$q$ & Oil flow rate & $\mathrm{m}^{3} / \mathrm{s}$ \\
$I$ & Solar radiation & $\mathrm{W} / \mathrm{m}^{2}$ \\
$n_{o}$ & Geometric efficiency & \\
$K_{o p t}$ & Optical efficiency & \\
$G$ & Collector aperture & $\mathrm{m}$ \\
$H_{l}$ & Global coefficient of thermal loss & $\mathrm{W} /\left(\mathrm{m}^{2 \circ} \mathrm{C}\right)$ \\
$H_{t}$ & Coefficient of heat transmission metal-fluid & $\mathrm{W} /\left(\mathrm{m}^{2 \circ} \mathrm{C}\right)$ \\
$L$ & Length of pipeline & $\mathrm{m}$ \\
\hline
\end{tabular}

The geometric efficiency depends on the hour angle, the solar time, the declination, the day of the year, the local latitude and the dimensions of the collector. The density $\rho$, the specific heat $C$ and the heat transfer coefficient $H_{t}$ depend on the temperature of the fluid. The coefficient of heat transmission depends on the temperature and oil flow [2]. The model is discretized in the longitudinal dimension of the tube, so the dynamics of each loop can be simulated as a chain of submodels. A segment length of 1 meter was chosen for the implementation of the simulation model (172 segments per loop).

\section{B. Lumped parameters model}

The concentrated parameter model provides a general description of the entire field. The variation in the internal energy of the fluid can be described by the equation:

$$
\begin{aligned}
C \frac{d T_{\text {out }}}{d t} & =K_{\text {opt }} n_{o} S I-q P_{c p}\left(T_{\text {out }}-T_{\text {in }}\right) \\
& -H_{l}\left(T_{m}-T_{a}\right)
\end{aligned}
$$

where $C$ is the thermal capacity of the loop, $K_{o p t}$ is the optical efficiency that takes into account elements such as reflectivity and absorptance. The geometric efficiency $n_{o}$ is determined by the position of the mirrors with respect to the vector of the radiation beam. The factor $P_{c p}$ takes into account some geometrical and thermal properties of the cycle. $T_{i n}$ is the inlet temperature, $H_{l}$ is the coefficient of global thermal losses, $T_{m}$ is the average temperature between the inlet and outlet temperature, and $T_{a}$ is the ambient temperature. The 
coefficient $H_{l}$ can be approximated by $1.05 \mathrm{~kW} /{ }^{\circ} \mathrm{C}, P_{c p}$ by $1,924 \times 10^{6} \mathrm{~kJ} /{ }^{\circ} \mathrm{C}, \mathrm{C}$ by $2267 \mathrm{~kW} /{ }^{\circ} \mathrm{C}$, and the total reflecting surface $S$ takes the value of $2674 \mathrm{~m}^{2}$. These values have been obtained based on the data related to the measures in the plant that work in different adjustment points by means of the multiple regression analysis [2].

\section{FUZZY ESTIMATOR OF LOOP SEGMENT TEMPERATURE}

For the training of the fuzzy system it is necessary to have a broad data set. This set of data will be divided into two parts: a first part will be dedicated to the training of the estimator and the second part will serve to make the check test used to check the error obtained with the designed system. The dataset will be created using the distributed parameter model. The solar field will be simulated by modifying the values of irradiance, geometric efficiency, ambient temperature and oil flow. Since it is not computationally feasible to have a set of data that contains all the nonlinear dynamics of the plant at any point of operation, the data set will be limited to obtain the variables in the steady state. Once the plant reaches the steady state, the value of the outlet temperature of the loop will be obtained as well as the temperature values of each segment of the pipe. Although the dataset includes values for irradiance, geometrical efficiency, etc., the training of the system is based only on the inlet and outlet temperature as well as the flowrate as inputs while the outputs are the temperatures of the different segments of the loops. Basically, the estimator will be trained based on the thermal jump that occurs in the loop and the oil flow. In this way given a flow and a thermal jump, the temperature of each piece can be estimated. This method of training the system has been chosen to reduce the data set and to avoid the explosion of rules since, at the end of the day, a thermal jump and a given flow rate will implicitly include other variables such as irradiance and geometric efficiency. For computational reasons, the loop is divided into 16 pieces instead of the 172 pieces into which the distributed parameter model is divided, both in the size of the fuzzy estimator and for its subsequent use, for example, in MPCs in the state space. The fuzzy estimation of the temperatures of the 16 segments is done with the same sampling time that is used in the plant controller, generally, $T_{s}=39 \mathrm{~s}$, [2]. Initially, to obtain the membership functions, it is useful to use a clustering method. Many algorithms come out for the clustering analysis [5], [10], [1], [20]. A fast single-iteration algorithm for estimating the number of clusters and the cluster centers of a data set is Subtractive Clustering (SC) [4]. This technique, like any grouping method, is used to obtain the appropriate linguistic variables. SC is a modification of the Mountain Method [21]. In $\mathrm{SC}$, the following function is defined

$$
M_{i}=\sum_{j=1}^{N} e^{-\alpha\left\|z_{i}-z_{j}\right\|^{2}}
$$

This function is called the mountain function, where $\alpha=4 / r_{a}^{2}$ and $r_{a}>0$ defines the neighborhood radius for each group (it is chosen according the desired groups resolution) .
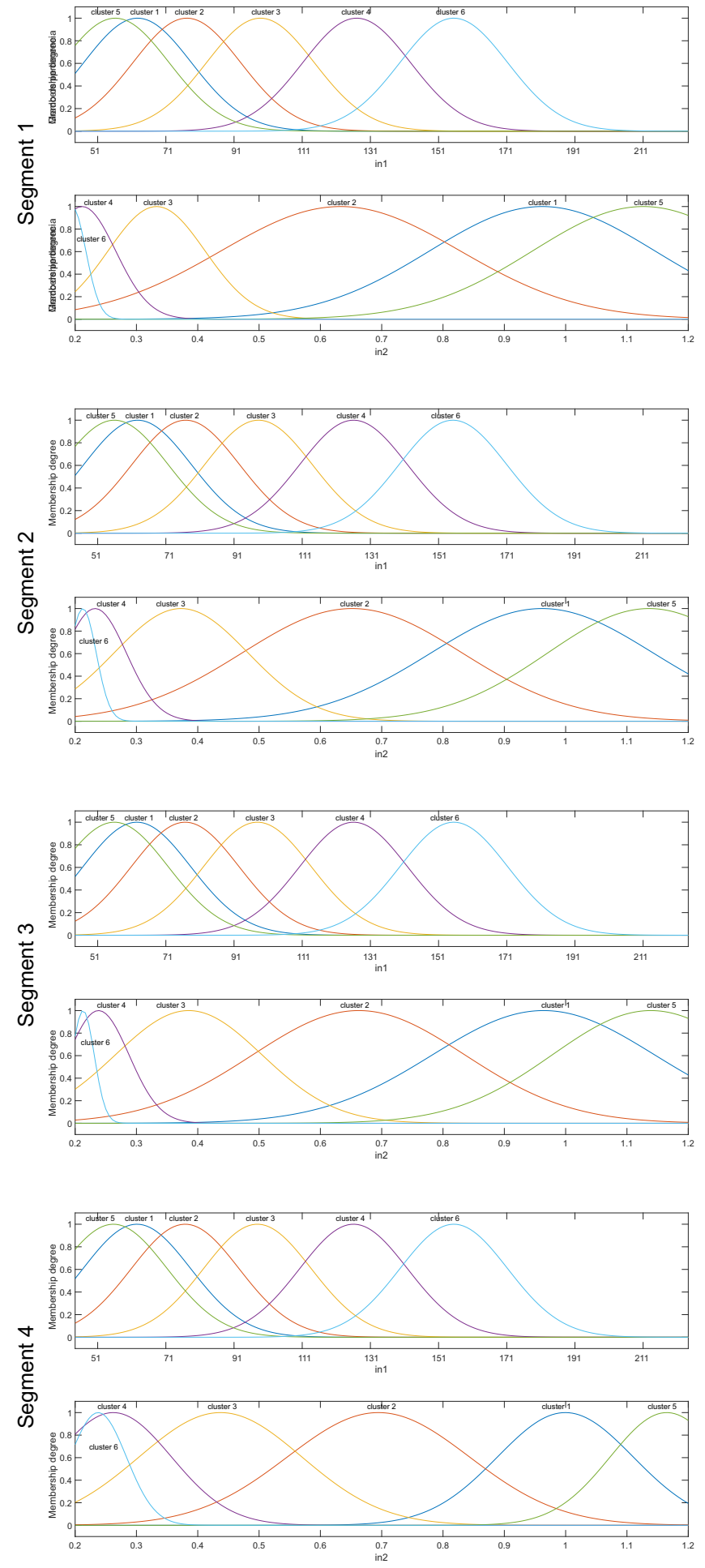

Fig. 2: Membership functions of fuzzy estimators

If $F_{1}^{*}$ is the highest value of the function, belonging to the point $z_{1}^{*}$, chosen as the center of the group, for each point $z_{i}$, the next reduced function is calculated,

$$
M_{i} \Longleftarrow M_{i}-M_{1}^{*} e^{-\beta\left\|z_{i}-z_{1}^{*}\right\|^{2}}
$$

The algorithm is the following: 


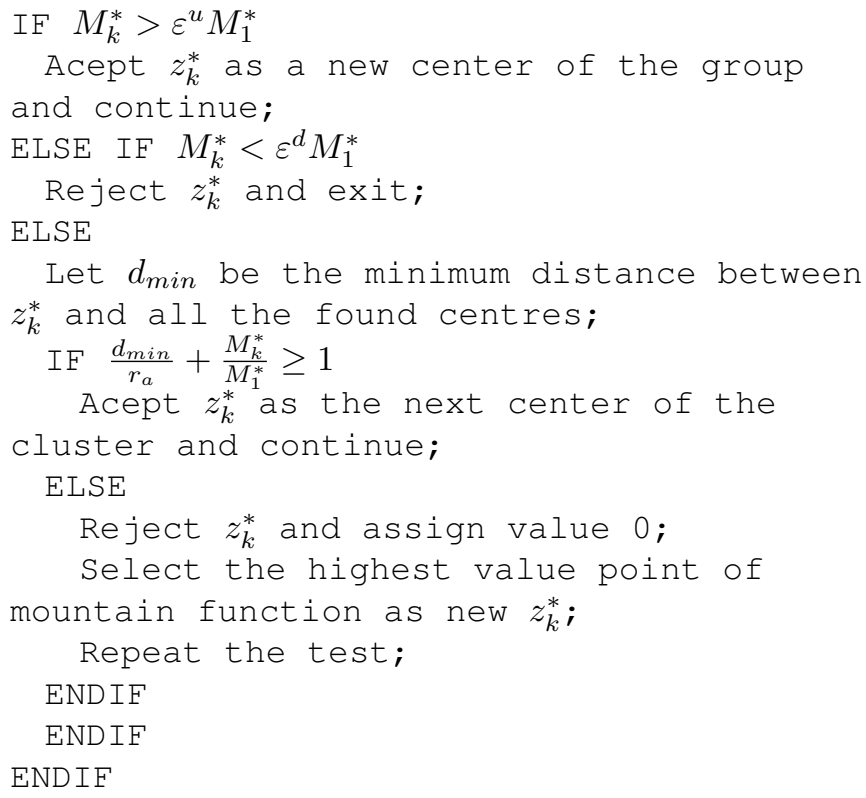

Where $\varepsilon^{u}$ is a threshold above which the point is selected as the center and $\varepsilon^{d}$ another threshold below which the point is discarded. Typically $\varepsilon^{u}=0.5$ and $\varepsilon^{d}=0.15$ (with normalized values). The radius for the reduced potential must have greater degree than the radius of the neighbor, to prevent spaced clusters. Normally $r_{b}=1.5 \cdot r_{a}$. Fig. 2 shows the resulting membership functions for each input (thermal jump and flow) and each segment. Similarities between the functions of each loop can be seen.

In Fig. 3, surfaces of the estimators are plotted against the measured values of temperature in each segment, together with a validation measure, such as the mean of the absolute value of the estimation error: $\overline{|e|}$. It can be seen that the last segment, being the outlet temperature, has zero error.

\section{RESULTS}

This section presents the results of the Fuzzy observer for the temperature estimation of the segments of different loops.

Acurex is a plant with 10 loops that can have different reflectivities due to dirt. The simulations have been carried out by applying a model-based controller whose mission will be to track a temperature reference at the field's outlet temperature. Since the plant consists of ten loops, the outlet temperature of the field will be the weighted average of the temperatures of all the loops that make up the field.

In the simulations, changes are made in the set-points of field outlet temperature to observe the estimation in different points of operation. Two simulations have been carried out with different set-points of temperature throughout the day. In these simulations, each loop has a different reflectivity, see Table II.

TABLE II: Simulated cases.

\begin{tabular}{lllllllllll}
\hline Reflectivities set & L1 & L2 & L3 & L4 & L5 & L6 & L7 & L8 & L9 & L10 \\
\hline Case 1 & 0.65 & 0.67 & 0.68 & 0.7 & 0.715 & 0.73 & 0.75 & 0.77 & 0.79 & 0.8 \\
Case 2 & 0.67 & 0.71 & 0.71 & 0.74 & 0.74 & 0.76 & 0.76 & 0.79 & 0.79 & 0.8 \\
\hline
\end{tabular}
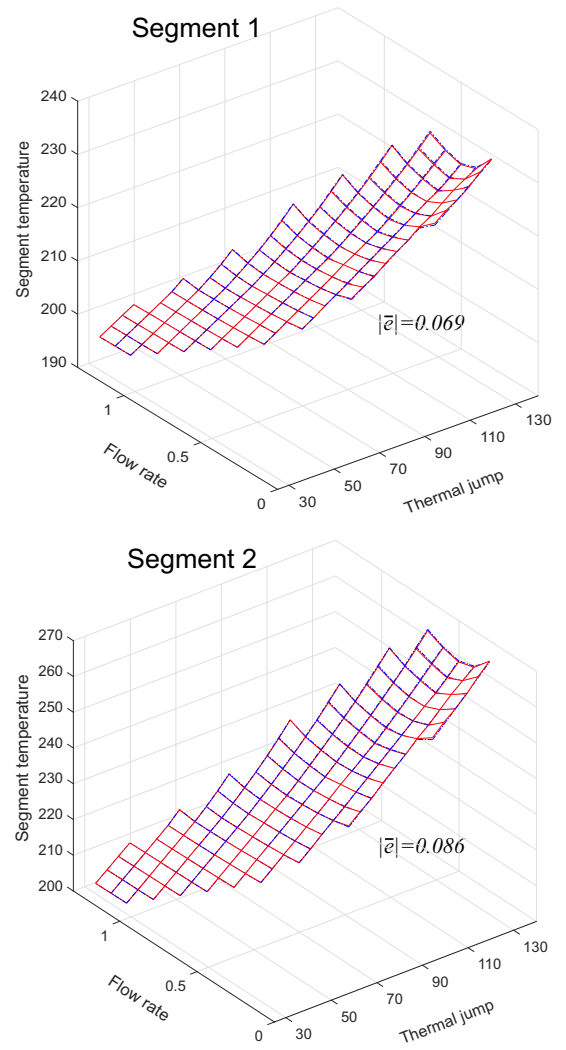

Segment 3
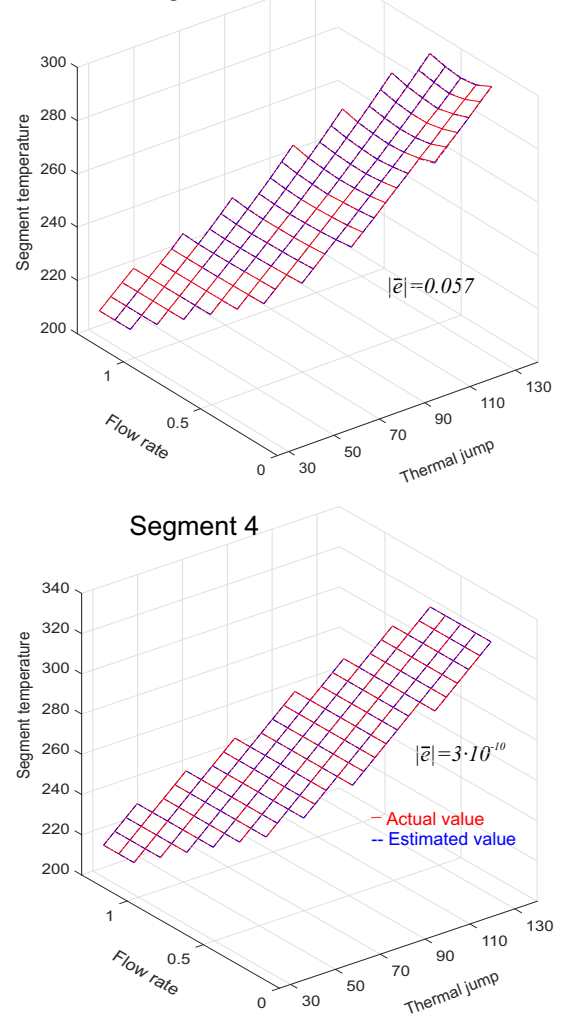

Fig. 3: Actual and estimated outlet temperature for each segment $\left({ }^{\circ} C\right)$. Inputs: Thermal jump $\left({ }^{\circ} C\right)$ and flow rate $\left(\mathrm{m}^{3} / \mathrm{s}\right)$

For visual and space reasons, the results of two of the 
ten loops with different reflectivities are presented, for each simulation, and the estimates of the 4 segments that correspond to each of the 4 collectors that make up a loop are presented. The first simulated scenario is presented in Figs. 4, 5 and 6. Fig. 4 presents the simulation of the operation of the flow-rate controller based on the model for case 1. It can be seen how it manages to keep a good tracking of the reference applied in the field outlet temperature. Fig. 5 shows the fuzzy estimation of the segments temperatures of loop 1, with a reflectivity of 0.65 . It is possible to observe that the estimator has a good performance in both dynamic and static.
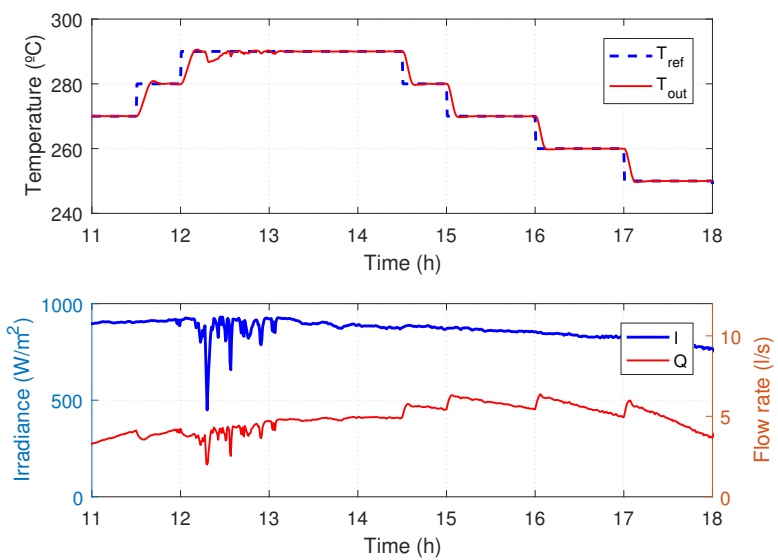

Fig. 4: Case 1: Field outlet temperature set-point tracking.
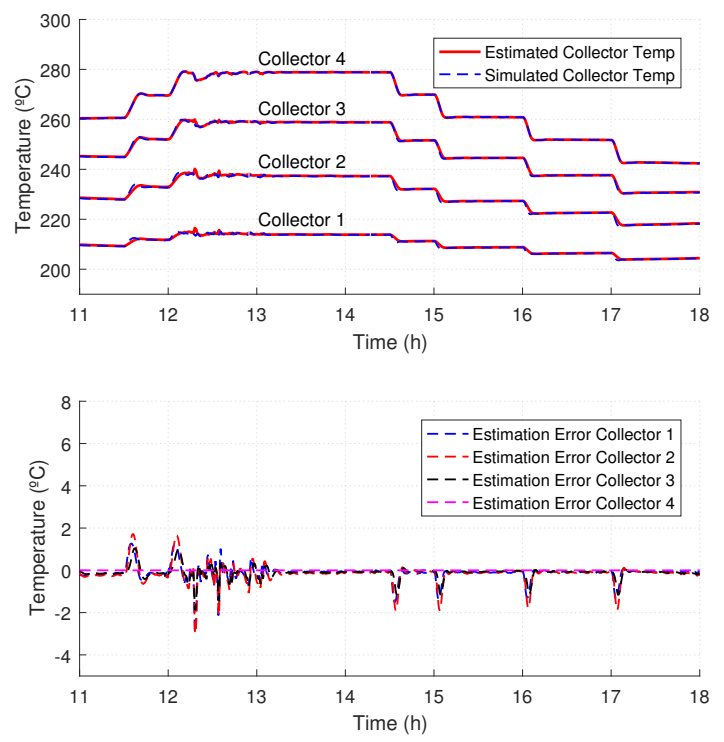

Fig. 5: Case 1: Loop 1 (reflectivity 0.65) temperatures estimation of 4 segments.

In Fig. 6 the fuzzy estimation of the temperatures of the segments of the loop 10 is presented, with a reflectivity of 0.8 .
It is observed that, although having a higher reflectivity, the estimator is capable of capturing it since the outlet temperature and loop input are being used as inputs to the fuzzy system. As explained above, when designing the estimator, data were used in steady state of the plant with changes in radiation, flow rate, ambient temperature, etc. Since only temperatures and flow were used for training, the reflectivity is implicitly included in the thermal jump that occur in the loop between inlet and outlet. This is reason for the estimation to be satisfactory in loops with different reflectivities.
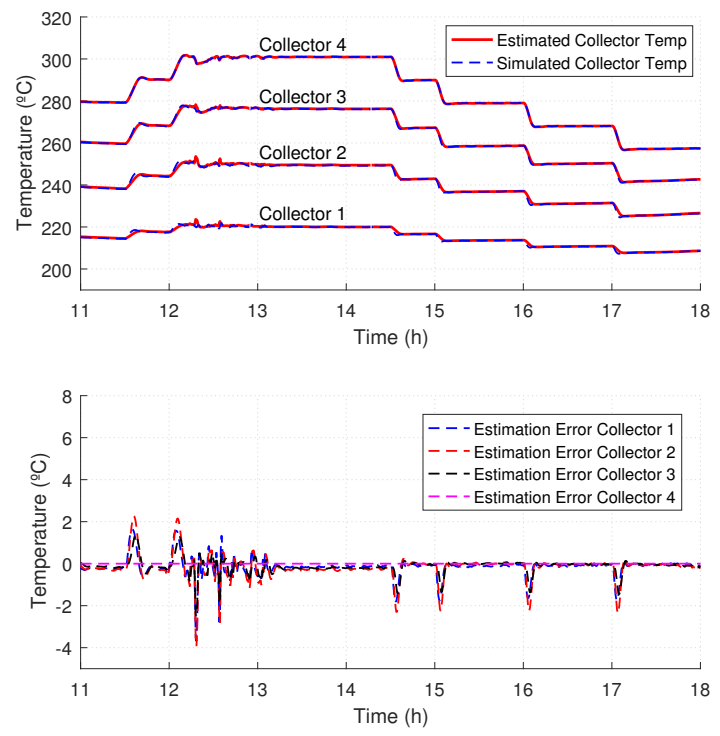

Fig. 6: Case 1: Loop 10 (reflectivity 0.8 ) temperatures estimation of 4 segments.

The second simulated scenario is presented in Figs. 7, 8 and 9. As before, the simulation of the operation of the modelbased controller of case 2 is presented, see Fig. 7 .
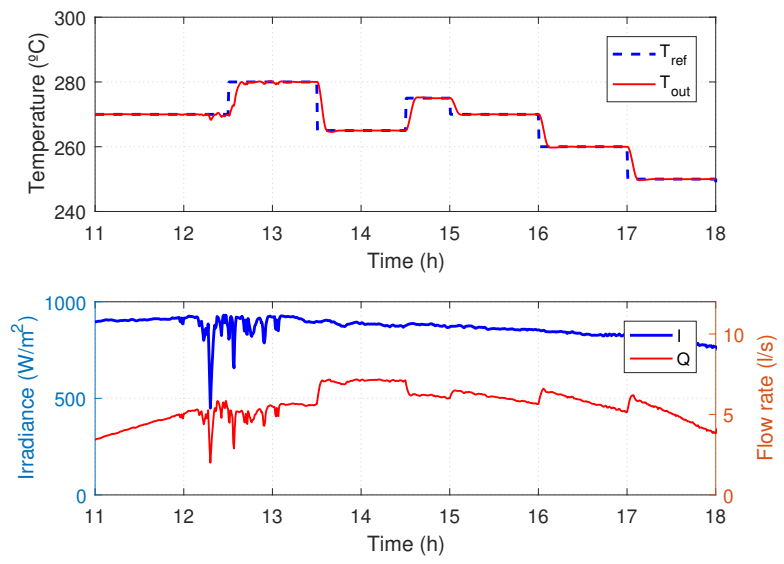

Fig. 7: Case 2: Field outlet temperature set-point tracking. 

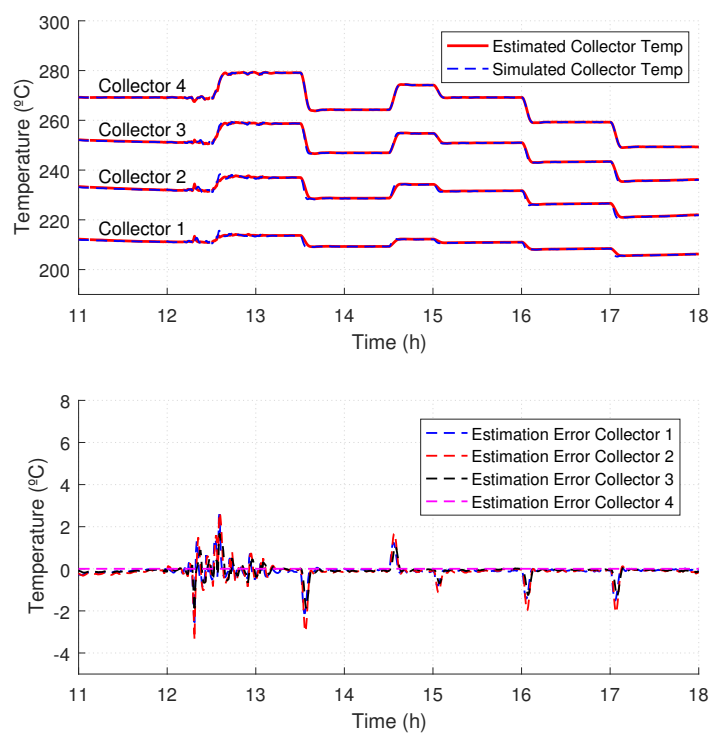

Fig. 8: Case 2: Loop 4 (reflectivity 0.74) temperatures estimation of 4 segments.
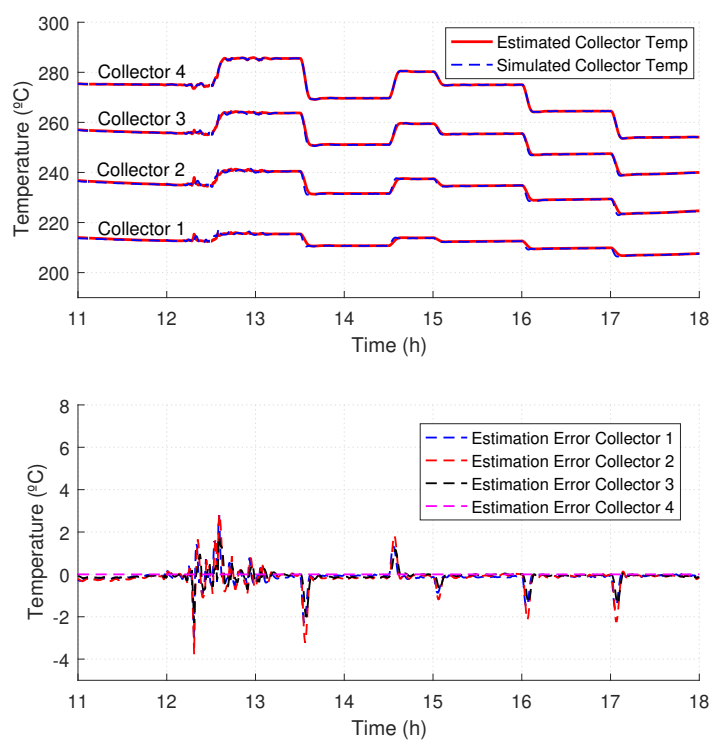

Fig. 9: Case 2: Loop 8 (reflectivity 0.79) temperatures estimation of 4 segments.

Figs. 8 and 9 show the results of the fuzzy estimation of the segments of loops 4 and 8, with reflectivities 0.74 and 0.79 respectively. Again, it is observed that the estimation is quite similar to the real behavior of the loop, both in the dynamic zone and in the steady state around the different operation points.

\section{CONCLUSION}

In this work, fuzzy estimators have been developed, made from operational data, using clustering techniques. They have been used for the temperature estimation of the segments of a parabolic trough solar plant. Two cases have been simulated in which different set-points of temperature are applied throughout the day. In these simulations each loop has a different reflectivity. The simulations show good performance at estimating the states of the loops even with different reflectivities.

\section{ACKNOWLEDGMENT}

The authors would like to acknowledge the VI Plan of Research and Transfer of the University of Seville (VI PPITUS) for funding this work and also to the European Research Council for the financial support under Advanced Research Grant OCONTSOLAR (789051).

\section{REFERENCES}

[1] Pavel Berkhin. Survey of clustering data mining techniques. Technical report, 2002.

[2] E. F. Camacho, M. Berenguel, and F. R. Rubio. Advanced Control of Solar Plants. Springer Science \& Business Media, 1997.

[3] R. Carmona. Analisis, modelado y control de un campo de colectores solares distribuidos con sistema de seguimiento en un eje. Ph.D. thesis. Universidad de Sevilla, 1985.

[4] S. Chiu. Fuzzy Model Identification based on cluster estimation. Journal of Intelligent Fuzzy Systems, 2:267-278, 1994.

[5] Brian S. Everitt, Sabine Landau, and Morven Leese. Cluster Analysis. Wiley Publishing, 4th edition, 2009.

[6] A. J. Gallego and E. F. Camacho. Adaptative state-space model predictive control of a parabolic-trough field. Control Engineering Practice, 20(9):904 - 911, 2012.

[7] A. J. Gallego, F. Fele, E. F. Camacho, and L. Yebra. Observer-based model predictive control of a parabolic-trough field. Solar Energy, 97:426 - 435, 2013.

[8] A. Ghosh and M. Chakraborty. Hybrid optimized back propagation learning algorithm for multi-layer perceptron. International Journal of Computer Applications, 57, 2012.

[9] Guzmán. 〈https://www.nrel.gov/csp/solarpaces/project_detail.cfm/ projectID $=18\rangle, 2018$.

[10] A. K. Jain, M. N. Murty, and P. J. Flynn. Data clustering: A review. ACM Comput. Surv., 31(3):264-323, September 1999.

[11] J.S.R. Jang. Anfis: adaptive-network-based fuzzy inference system. IEEE Transactions on Systems, Man, and Cybernetics, 23(3):665-685, May 1993.

[12] Mohammad Karamali and Mahdi Khodabandeh. A distributed solar collector field temperature profile control and estimation using inlet oil temperature and radiation estimates based on iterative extended kalman filter. Renewable Energy, 101:144 - 155, 2017.

[13] Kaxu Solar One. 〈https://www.nrel.gov/csp/solarpaces/project_detail. $\mathrm{cfm} /$ projectID $=245\rangle, 2018$.

[14] A. J. Sánchez, A. J. Gallego, J. M. Escaño, and E. F. Camacho. Temperature homogenization of a solar trough field for performance improvement. Solar Energy. Elsevier, 165C:1-9, 2018.

[15] A.J. Sánchez, J.M. Escaño, C. Bordons, and E.F. Camacho. Estimador borroso de una planta solar cilindro-parabólica. In A.J. Calderón Godoy I. González Pérez P. Merchán García J. Lozano Rogado S. Salamanca Miño y B.M. Vinagre Jara I. Tejado Balsera, E. Pérez Hernández, editor, Actas de las XXXIX Jornadas de Automática, pages 908-915, Badajoz, 2018. Universidad de Extremadura.

[16] Solana Generating Station. 〈https://www.nrel.gov/csp/solarpaces/ project_detail.cfm/projectID=23〉, 2018.

[17] Solar Millennium AG. The construction of the andasol power plants. 〈http://www.solarmillennium.de/english/archives/technology/ references-and-projects/andasol-spain/andasol_artikel.html $\rangle, 2018$.

[18] Tomohiro Takagi and Michio Sugeno. Fuzzy identification of systems and its applications to modeling and control. IEEE Transactions on Systems, Man, and Cybernetics, 15(1):116-132, January 1985.

[19] P. J. Werbos. Beyond Regression: New Tools for Prediction and Analysis in the Behavioral Sciences. PhD thesis, Harvard University, 1974. 
[20] Rui Xu and II Wunsch, D. Survey of clustering algorithms. Neural Networks, IEEE Transactions on, 16(3):645-678, May 2005.

[21] R. R. Yager and D. P. Filev. Approximate clustering via the mountain method. IEEE Transactions on Systems, Man, and Cybernetics, 24(8):1279-1284, Aug 1994. 